\title{
Improving the analysis of biogeochemical patterns associated with internal waves in the Strait of Gibraltar using remote sensing images.
}

Gabriel Navarro ${ }^{1 *}$, Jorge Vicent ${ }^{2}$, Isabel Caballero ${ }^{1,3}$, Jesús Gómez-Enri ${ }^{4}$, Edward P. Morris ${ }^{4,5}$, Neus Sabater ${ }^{2}$, Diego Macías ${ }^{6}$, Marina Bolado-Penagos ${ }^{4}$, Juan Jesús GomizPascual $^{4}$, Miguel Bruno ${ }^{4,5}$, Rui Caldeira ${ }^{7}$ and Águeda Vázquez ${ }^{8}$.

${ }^{1}$ Instituto de Ciencias Marinas de Andalucía, ICMAN-CSIC, Puerto Real, 11510, Cádiz, Spain.

${ }^{2}$ Laboratory for Earth Observation, University of Valencia, 46980, Valencia, Spain.

${ }^{3}$ National Oceanic and Atmospheric Administration, Silver Spring, MD 20910, United States.

${ }^{4}$ Facultad de Ciencias del Mar y Ambientales, Universidad de Cádiz, Campus de Puerto Real S/N, Puerto Real, 11510 Cádiz, Spain.

${ }^{5}$ Centro Andaluz de Ciencia y Tecnología Marinas (CACYTMAR), Universidad de Cádiz, Campus de Puerto Real S/N, Puerto Real, 11510 Cádiz, Spain.

${ }^{6}$ European Commission, Joint Research Centre, Directorate D. Via E. Fermi 2749, Ispra, 21027 Varese, Italy.

${ }^{7}$ Observatório Oceânico da Madeira, OOM-ARDITI, 9020-105, Funchal, Portugal.

${ }^{8}$ Escuela Superior de Ingeniería, Universidad de Cádiz, Campus de Puerto Real S/N, Puerto Real, 11510 Cádiz, Spain.

\section{* Corresponding author:}

Gabriel Navarro

Department of Ecology and Coastal Management 
Institute of Marine Sciences of Andalusia (ICMAN-CSIC)

Avda. Republica Saharaui, 2

11510- Puerto Real

Cádiz

Spain

e-mail: gabriel.navarro@icman.csic.es

Tel: +34 $956832612 \operatorname{ext} 235$

Fax: +34956834701

Key words: high amplitude internal waves, Strait of Gibraltar, Algeciras Bay, Sentinel2, $\mathrm{HICO}$ 


\section{Abstract.}

High Amplitude Internal Waves (HAIWs) are physical processes observed in the Strait of Gibraltar (the narrow channel between the Atlantic Ocean and the Mediterranean Sea). These internal waves are generated over the Camarinal Sill (western side of the strait) during the tidal outflow (toward the Atlantic Ocean) when critical hydraulic conditions are established. HAIWs remain over the sill for up to 4 hours until the outflow slackens, being then released (mostly) towards the Mediterranean Sea. These have been previously observed using Synthetic Aperture Radar (SAR), which captures variations in surface water roughness. However, in this work we use high resolution optical remote sensing, with the aim of examining the influence of HAIWs on biogeochemical processes. We used hyperspectral images from the Hyperspectral Imager for the Coastal Ocean (HICO) and high spatial resolution (10 m) images from the MultiSpectral Instrument (MSI) onboard the Sentinel-2A satellite. This work represents the first attempt to examine the relation between internal wave generation and the water constituents of the Camarinal Sill using hyperspectral and high spatial resolution remote sensing images. This enhanced spatial and spectral resolution revealed the detailed biogeochemical patterns associated with the internal waves and suggests local enhancements of productivity associated with internal waves trains. 


\section{Introduction.}

The Strait of Gibraltar constitutes the only connection between the Mediterranean Sea and the North Atlantic Ocean, making it a special site for observing the temporal evolution of Mediterranean waters (Flecha et al., 2015), which play a major role in the global circulation and biogeochemistry of the basin (Millot, 1999; Millor and Taupier-Letage, 2005). Water circulation in the Strait is "inverse-estuarine", with surface inflow of Atlantic waters and deep outflow of denser Mediterranean waters. This pattern is ultimately driven by an excess of evaporation compared to precipitation in the basin (Lacombe and Richez, 1982) and by the transformation of surface waters into deep waters during deep winter convection events (e.g., Macías et al., 2016). The Strait (Fig. 1) is about $60 \mathrm{~km}$ long, $15 \mathrm{~km}$ wide at its narrowest section (the Tarifa narrows), and only $280 \mathrm{~m}$ depth at its main sill (Camarinal Sill, Fig. 1b). One of the most interesting phenomena in the Strait is the generation of High Amplitude Internal Waves (HAIWs, henceforth) over the Camarinal Sill. HAIWs modify the sea surface roughness in the Strait, provoking a phenomenon popularly known as "boilingwater" or "hervideros" as described by Tofiño (1832) based on reports by local sailors and fishermen.

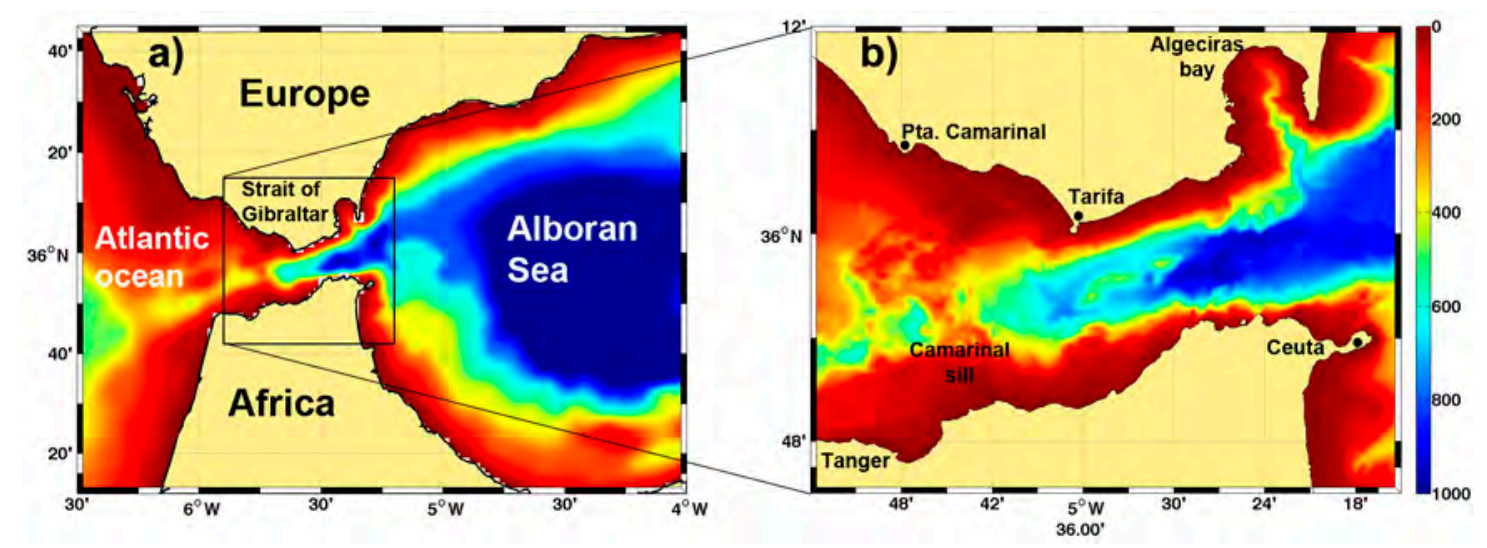

Fig. 1. a) Map of the studied zone. b) Zoom showing the main topographic features of the Strait of Gibraltar. Colours indicate the bathymetry in meters. 
Within the Strait of Gibraltar is Algeciras Bay (Fig. 1b, $73 \mathrm{~km}^{2}$ ) with a bathymetry characterized by a central canyon that reaches a maximum depth of $450 \mathrm{~m}$. Despite the large amount of oceanographic data collected in the Strait of Gibraltar, there is a lack of field measurements and numerical results in Algeciras Bay. HAIWs have been observed in the mouth of the bay (Watson and Robinson, 1990; 1991), suggesting they may affect its circulation (Alvarez et al., 2011). Indeed recently, Chioua et al. (2013) analysed the role of HAIWs in the vertical mixing processes within the Algeciras Bay. The generation and propagation of HAIWs modifies currents, which in turn affect sea surface roughness (Alpers, 1985). This surface effect makes it possible to detect internal waves in various parts of the electromagnetic spectrum using remote sensing techniques (Klemas, 2012). In this study, we analyse HAIWs in the Strait of Gibraltar and Algeciras Bay using high spatial resolution images from the MultiSpectral Instrument (MSI) on board the Sentinel-2A (S2A) satellite and hyperspectral images from the Hyperspectral Imager for the Coastal Ocean (HICO) on the International Space Station (ISS). The Sentinel-2 mission provides continuity to services relying on multispectral high spatial resolution optical observations over global terrestrial surfaces (Martimort et al., 2007; Drusch et al., 2012), providing enhanced continuity of SPOT (Satellite Pour l'Observation de la Terre) and Landsat-type data. S2A carries an optical payload (MSI) with visible, near infrared and shortwave infrared sensors comprised of 13 spectral bands: 4 bands at $10 \mathrm{~m}, 6$ bands at $20 \mathrm{~m}$ and 3 bands at $60 \mathrm{~m}$ spatial resolution, with a combined swath width of $290 \mathrm{~km}$. However, as the number of bands with high spatial resolution $(10 \mathrm{~m})$ in $\mathrm{S} 2 \mathrm{~A}$ is limited (4 bands, Malennovsky et al., 2012), it does not allow for a variety of products related to ocean colour to be obtained. On the contrary, the HICO sensor provides detailed information in the visible region 
and has been successfully used to analyse HAIWs in the Strait of Gibraltar (Szekielda, 2012). Hyperspectral remote sensing of water penetrating wavelengths $(400-900 \mathrm{~nm})$ allows the observation of many coastal characteristics, including depth and bottom type (MacKinna et al., 2012), and concentrations of colored dissolved organic matter, suspended sediments and chlorophyll (Gitelson et al., 2011). Additionally, the presence of phytoplankton accessory pigments could potentially be determined, providing information on the types and quantities of phytoplankton in the water (Dierssen et al., 2015). This information can be used to identify harmful algae, quantify biogeochemical cycles, and assess the trophic status of the ecosystem (Szekielda et al., 2009; Ryan et al., 2014). In the case of internal waves, hyperspectral remote sensing potentially provides a means to simultaneously examine both physical and biological effects on upwelling radiance.

HAIWs in the Strait are generated by the interaction of the barotropic tide with the abrupt topography of the Camarinal Sill in the presence of such strong stratification and, often after a delay, propagate mainly towards the Mediterranean Sea. HAIWs are produced during critical and supercritical hydraulic conditions, defined by the Froude number (Hibiya, 1986) as $F(t)=C / U(t)$, where $U(t)$ is the velocity of barotropic flow and $C$ is the linear phase speed of the first baroclinic mode. These internal disturbances decompose into wave trains during the propagation and their structure has been described extensively (Armi and Farmer, 1988; Tsimplis, 2000; Izquierdo et al., 2001; Bruno et al., 2002). As discussed in Vázquez et al. (2008), the trapping of internal waves on the lee side of the Camarinal Sill is caused when critical or supercritical conditions are established over the Sill, when the outflow towards the Atlantic Ocean is around $1 \mathrm{~m} / \mathrm{s}$ (Bruno et al., 2013). The release of the internal waves towards the Alboran Sea begins with the establishment of subcritical conditions over the Sill. This 
happens almost at the start of the eastward phase of the barotropic tidal currents and can be modelled using TIDEX simulations (Vázquez et al., 2006; Vazquez et al., 2008; Chioua et al., 2013).

The effects of HAIWs are diverse, including alterations of biogeochemical patterns (Bruno et al., 2002; Macías et al., 2006; Ramírez-Romero et al., 2014), enhancement of fisheries (Gil, 2006), and even submarine accidents (Pinet, 2009). However, most studies focus on physical-biological coupling; HAIWs are one of the major contributors to the mixing between the Atlantic and Mediterranean water layers in the Strait (Wesson and Gregg, 1994; Macías et al., 2006; 2007). In fact, Bartual et al. (2011) found evidence of a change in the phytoplankton primary production pattern concomitant with the presence of an internal bore in the main channel of the Strait, which was consistent with the arrival of active coastal plankton communities. These coastal, chlorophyll-enriched waters are advected towards the Mediterranean Sea (e.g. Ramírez-Romero et al., 2012), which explains the pulsating patterns of chlorophyll in the Atlantic Jet (Macías et al., 2006). This hypothesis was later confirmed by Vázquez et al. (2009), who used in-situ data and satellite images to show how the generation of internal waves induced the transport of chlorophyll-enriched coastal waters to the channel and their advection towards the Alboran Sea. Therefore, these coastal waters could modify the water surface reflectance characteristics (Novoa et al., 2015).

Consequently, the objective of this study is to present the use of new optical satellite images such as HICO (hyperspectral) and S2A (high spatial resolution) ones, to analyse biogeochemical patterns associated with internal waves and their relationship with the physical conditions in the Strait of Gibraltar. Until now, only studies using Synthetic Aperture Radar (SAR) images (Vázquez et al., 2004; Alpers et al., 2008) and 
ocean colour images with medium spatial resolution (Szekielda, 2012; Vázquez et al., 2009) have been used to analyse the internal wave activity in the Strait of Gibraltar.

\section{Material and Methods.}

\subsection{Satellite measurements.}

\subsubsection{Sentinel-2 data.}

S2A satellite was launched by European Space Agency (ESA) on 23 June 2015, the first of the two-satellite Sentinel-2 missions. The final constellation will provide a revisit time of five days at the Equator and will be proportionately more frequent in higher latitudes. The Sentinel-2 mission is ensuring long-term observational commitment and will operate a range of instruments with different spectral bands and spatial resolutions with global coverage and high revisit times (Berger et al., 2012). The 13 spectral bands span from visible (VIS) and near infrared (NIR), to short wave infrared (SWIR), with spatial resolutions ranging from 10 to $60 \mathrm{~m}$ (Malenovsky et al., 2012).

Level-1C (L1C) images (radiometric and geometric corrected Top Of Atmosphere (TOA) products with a UTM projection and WGS84 ellipsoid) for 8 March 2016 at 11:20 UTC and 7 April 2016 at 11:12 were downloaded from the Sentinel's Scientific Data Hub (https://scihub.copernicus.eu/) (Table 1). These were processed to Level-2A using the open source (OS) Sentinel-2 Toolbox (Sentinel Application Platform, SNAP v2.0.2., http://step.esa.int/main/download/). Specifically, an atmospheric correction procedure was executed using the Sen2Cor plugin (Sentinel 2 Correction, v2.2.1, http://step.esa.int/main/third-party-plugins-2/sen2cor/), which is a prototype processor for Sentinel-2 Level-2A (L2A) product formatting and processing. Although Sen2Cor was not designed for water bodies, it will probably be the first choice for many users due to its availability in the toolbox (Toming et al., 2016). 
Sen2Cor performs a pre-processing of L1C TOA image data, and applies a scene classification and atmospheric, terrain and cirrus correction and a subsequent conversion into an ortho-image L2A Bottom-Of-Atmosphere (BOA) reflectance product. L2A products are re-sampled as the L1C products with a constant GSD (Ground Sampling Distance) of $10 \mathrm{~m}, 20 \mathrm{~m}$ and $60 \mathrm{~m}$ according to the native resolution of the different spectral bands. Further mosaicking of images was carried out using the OS Geographic Information System (GIS), QGIS (v2.14.0, http://www.qgis.org). Figures shown here are Band 4 (665 nm, $10 \mathrm{~m}$ spatial resolution).

\subsubsection{HICO data.}

The HICO sensor was operated on the ISS during five years (between September 2009 and September 2014) and was specifically designed for environmental characterization of the coastal ocean from the space (Lucke et al., 2011). HICO images covered an area approximately $42 \mathrm{~km}$ wide and $192 \mathrm{~km}$ long (Ryan et al., 2014) with a spatial resolution of $\sim 90 \mathrm{~m}$ and 87 spectral channels covering the visible and nearinfrared range from 400 to $900 \mathrm{~nm}$ with a spectral resolution of $5.7 \mathrm{~nm}$ (Lucke et al., 2011). This range includes visible light (400-700 $\mathrm{nm})$, which penetrates the water and provides information on water properties and bottom reflectance; and shortwave infrared radiation $(700-900 \mathrm{~nm})$, which is used to correct for atmospheric aerosols and surface reflectance (Corson and Davis, 2011; Lucke et al., 2011).

Three Level 1b (L1b) images acquired by HICO (Table 1) and downloaded from the OceanColor website (http://oceancolor.gsfc.nasa.gov/) were analysed to identify biogeochemical patterns and ocean colour characteristics of the internal waves in the Strait of Gibraltar. In order to obtain remote sensing reflectance, HICO L1b images were processed using the HICO toolbox developed by Vicent et al. (2015), which includes three main sequential steps. 
Firstly, L1b images are pre-processed in order to keep consistency with the atmospheric inversion model and reduce the impact of instrument calibration errors and stray-light. This first step is based on a radiometric vicarious re-calibration of the HICO L1b TOA radiances against in-situ reflectance measurements propagated to TOA using the MODTRAN atmospheric radiative transfer model (Berk et al., 2006). Secondly, HICO L1b data is used to characterize the atmospheric state of the acquired image through the retrieval of aerosol properties and columnar water vapour. The aerosol properties (modelled by its optical depth, Angstrom exponent and Henyey-Greenstein phase function parameter) are retrieved through a MODTRAN model inversion technique based on the work done by Guanter et al. (2008). The retrieval of these parameters was initialized, when available, with the aerosol optical thickness data from the AERONET stations of Huelva and Málaga at times correlating to the sensor overpass. The retrieval of columnar water vapour is based on the Linear Regression Ratio (LIRR) algorithm (Schläpfer et al., 1996) through the differential absorption at $820 \mathrm{~nm}$. The retrieved columnar water vapour is inverted pixel-wise by comparison between measured (i.e., with HICO L1b data) and MODTRAN-simulated LIRR ratios. Then, surface reflectance is inverted assuming a Lambertian surface given HICO's nearnadir observation geometry. Lastly, we employed the ALBOC3 algorithm (GómezJakobsen et al., 2016) for characterizing chlorophyll concentration.

\subsubsection{Other satellite data.}

In addition, SAR images (Table 1) were obtained from the European Remote Sensing Satellite 1 and 2 (ERS-1 and ERS-2). The scenes were multi-looked (speckle reduced), VV-polarized and acquired in Image Mode (geocoded ellipsoid corrected). The pixel resolution is about 25-30 m. MEdium Resolution Imaging Spectrometer (MERIS) and Moderate Resolution Imaging Spectroradiometer (MODIS) Level-2 
images (Table 1) were downloaded from the OceanColor website (http://oceancolor.gsfc.nasa.gov/) and processed using SeaDAS version 7.3 to compare the ocean colour products (e.g. chlorophyll concentration). MODIS and MERIS chlorophyll images were computed using the standard algorithms OC3M (O'Reilly et al., 2000) and OC4ME (Morel and Antoine, 2000), respectively.

Table 1. Set of processed Sentinel-2 (S-2), HICO, MERIS, MODIS and SAR images

\begin{tabular}{cccccc}
\hline Sensor & Platform & Filename & Level & Date & Time \\
\hline MSI & S2A & S2A_OPER_PRD_MSIL1C_PDMC ... & L1C & $03 / 08 / 16$ & $11: 20$ \\
MSI & S2A & S2A_OPER_PRD_MSIL1C_PDMC .. & L1C & $04 / 07 / 16$ & $11: 12$ \\
HICO & ISS & H2009339142952.L1B_ISS & L1b & $12 / 05 / 09$ & $14: 29$ \\
HICO & ISS & H2010308152407.L1B_ISS & L1b & $11 / 04 / 10$ & $15: 24$ \\
HICO & ISS & H2011268104401.L1B_ISS & L1b & $09 / 25 / 11$ & $10: 44$ \\
MERIS & Envisat & M2010308105938.L2_FRS_OC.x.hdf & L2 & $11 / 04 / 10$ & $10: 59$ \\
MODIS & Aqua & A2010308130000.L2_LAC_OC & L2 & $11 / 04 / 10$ & $13: 00$ \\
SAR & ERS-1 & SAR_IMG_1PXASI19930108_110511.E1 & L2 & $01 / 08 / 93$ & $11: 05$ \\
SAR & ERS-1 & SAR_IMG_1PXASI19940108_110331.E1 & L2 & $01 / 08 / 94$ & $11: 03$ \\
SAR & ERS-1 & SAR_IMG_1PXASI19940120_110333.E1 & L2 & $01 / 20 / 94$ & $11: 03$ \\
SAR & ERS-1 & SAR_IMG_1PXASI19960324_223903.E1 & L2 & $03 / 24 / 96$ & $22: 39$ \\
SAR & ERS-2 & DAT_01.001 & L2 & $11 / 12 / 03$ & $11: 00$ \\
\hline
\end{tabular}

\subsection{Ancillary data.}

Predictions of tidal current (45 m depth) were made from 38 harmonic constants derived from the harmonic analysis of long term velocity records measured using an Acoustic Doppler Current Profiler (ADCP) deployed at the Camarinal Sill during the Strait 94-96 Experiment (Vázquez et al., 2006). Positive values of tidal elevation represent currents towards the Mediterranean Sea, whereas negative are towards the Atlantic Ocean. This method adequately reproduces the behaviour of the currents at the Camarinal Sill, although it does not capture the enhancement and dampening of the 
subinertial flow produced by high and low atmospheric pressure over the western Mediterranean Sea (Candela et al., 1989; Vázquez et al., 2008; Chioua et al., 2017).

Atmospheric pressure data were downloaded from the ERA-Interim European Centre for Medium-Range Weather Forecast (ECMWF) web site (http://www.ecmwf.int). The data corresponding to 9 locations in the western Mediterranean Sea $\left(42.5^{\circ}-37.5^{\circ} \mathrm{N}, 2.5^{\circ}-7.5^{\circ} \mathrm{E}\right)$ were averaged to analyse the influence of the atmospheric pressure on the generation of HAIWs.

\section{Results and Discussion.}

\subsection{HAIWs characterization using SAR images.}

SAR images in the Strait of Gibraltar show the typical evolution of HAIWs (Fig. 2), their generation over the Camarinal Sill (Fig. 2a), the propagation initiation (Fig. 2c), and advanced propagation towards the Alboran Sea (Fig. 2e, $2 \mathrm{~g}$ and $2 \mathrm{j}$ ). At the front of the internal wave, the roughness of the internal waves increased, whereas towards the rear it decreased. This is the reason why, on SAR images, the front section of an internal wave is bright and the rear section is dark (Alpers, 1985; Alpers et al., 2008). Note this sequence of images does not correspond to the same event. Each image is accompanied by a prediction of surface currents (at $45 \mathrm{~m}$ depth) at the Camarinal Sill, with the moment at which the image was acquired highlighted (Fig. 2b, 2d, 2f, $2 \mathrm{~h}$ and $2 \mathrm{j}$ ). The trapping of internal waves on the lee side of the Camarinal Sill is caused by the establishment of critical or supercritical conditions over the Sill (Vázquez et al., 2008), when the outflow towards the Atlantic Ocean is around $1 \mathrm{~m} / \mathrm{s}$ (Bruno et al., 2013). The release of the internal waves towards the Alboran Sea begins with the establishment of subcritical conditions over the Sill and happens almost at the start of the eastward phase of the barotropic tidal currents. 
In the first image (Fig. 2a), two well-defined bands situated over the Camarinal Sill are observed during the maximum westward tidal flow $(\sim 1.8 \mathrm{~m} / \mathrm{s}$ around 11:00 UTC, Fig. 2b). These HAIWs were generated when the westward flow reached $1 \mathrm{~m} / \mathrm{s}$ (Vázquez et al., 2008), at about 10:00 UTC on 8 January 1993 (Fig. 2b).

In the following image (Fig. 2c), coinciding with the change of current direction in the Strait, the HAIWs are displaced slightly with respect to their initial location, indicating the first moments of propagation towards the Mediterranean in the east. In this case harmonic-based predictions of tidal velocity were not as intense as the previous ones (Fig. 2d). This finding may be explained by taking into account the modification of the hydraulic conditions over the Sill produced by subinertial flow variations, forced by atmospheric pressure fluctuations in the western Mediterranean (Vázquez et al., 2008). An increase of atmospheric pressure in the western Mediterranean Sea in the preceding period (since 7 January 1994, Fig. 3, red line) acted to intensify the westward flow leading to the establishment of the critical conditions necessary for internal wave generation (Vázquez et al., 2008). This mechanism is responsible for the activation of internal wave events during neap tides, and inhibition during spring tides. Vázquez et al. (2008) demonstrated that an increase in the atmospheric pressure over the western Mediterranean promotes the occurrence of critical or supercritical conditions there, even when the maximum westward tidal current has an intensity of less than $1 \mathrm{~m} / \mathrm{s}$. 


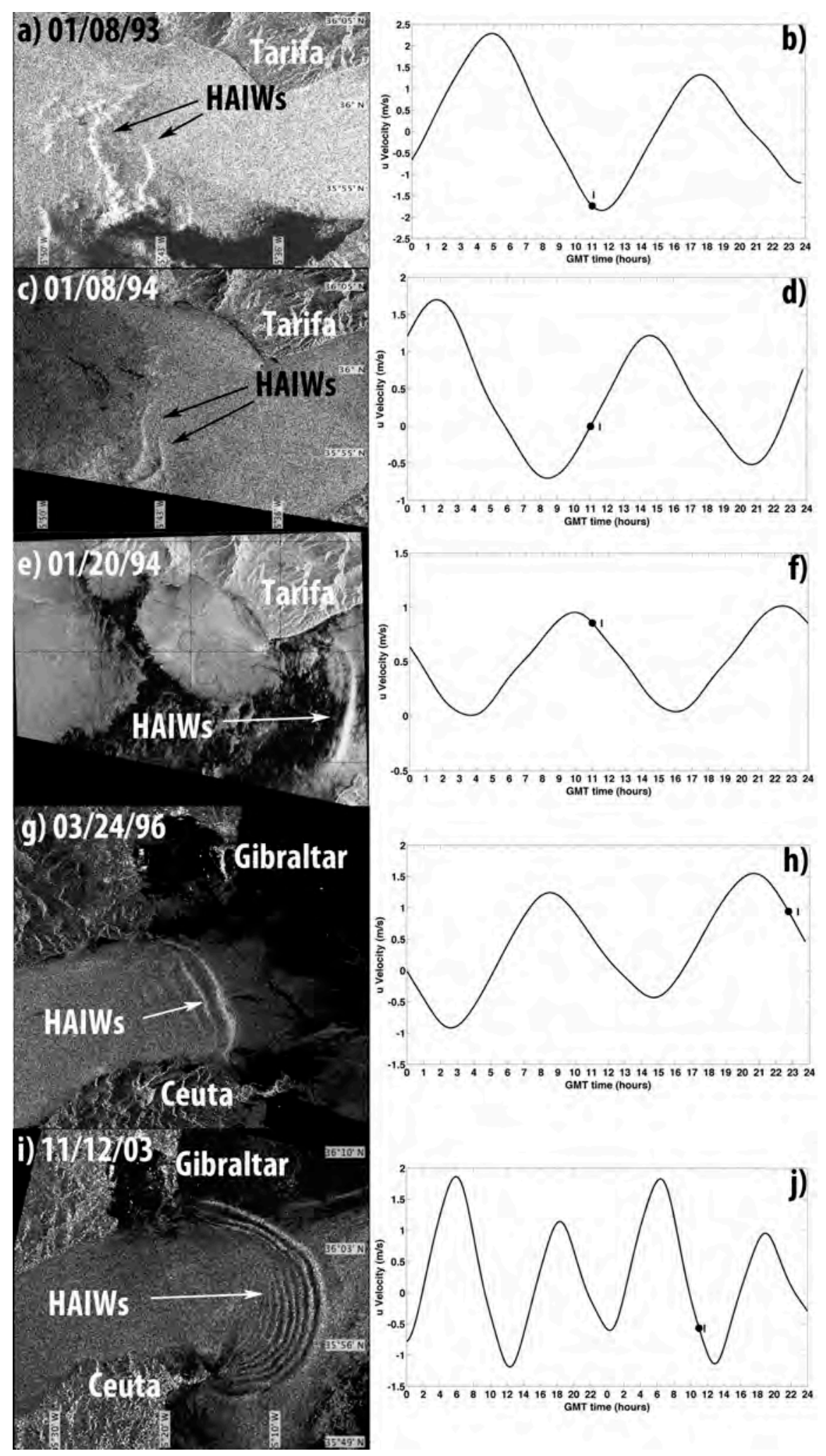

Fig. 2. SAR images (a, c, e, g, and i) accompanied by current tidal prediction (b, d, f, h, and $\mathrm{j}$ ) for several dates. Dots (I) represent at the time when SAR images were captured. The predicted time for the release of internal waves from Camarinal Sill are identified $(\mathrm{R})$. 
The third and fourth images (Fig. 2e and 2g), captured after maximum eastward flow before the current direction has reversed (Fig. $2 \mathrm{f}$ and $2 \mathrm{~h}$ ), show a well-defined surface roughness signal representing an internal wave train that has travelled east as far as the Algeciras Bay (Fig. 2e, 24 March 1996). These HAIWs were generated over the Sill around 8 hours before the SAR image was acquired (Fig. $2 \mathrm{f}$ and $2 \mathrm{~h}$ ) and, as the above example, the high atmospheric pressure in the western Mediterranean contributed to enhanced tidal current velocities and is the mechanism responsible for the activation of internal wave events during neap tides (Fig. 3). Finally, the last image represents the propagation of the internal waves into the Alboran Sea (Fig. 2i, 12 November 2003), showing sea surface manifestations (or radar signatures) of an internal solitary wave packet consisting of more than 6 long internal waves. These internal waves were released about 01:00 UTC on 11 November 2003 (Fig. 2j).

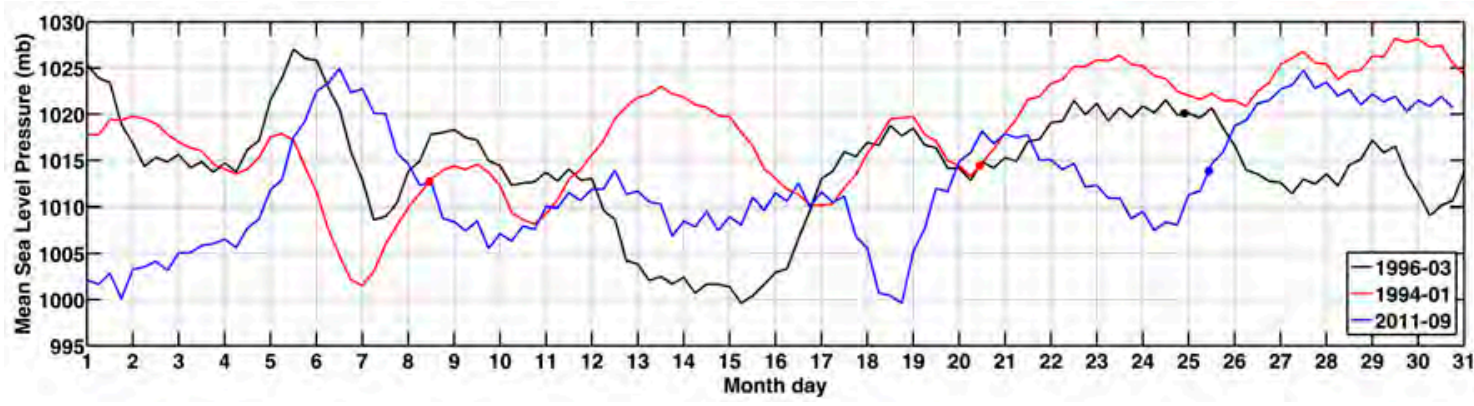

Fig. 3. Atmospheric pressure in western Mediterranean corresponding to March 1996 (black), January 1994 (red) and September 2011 (blue). Dots represent the time when the corresponding satellite image were captured.

The joint analysis of the SAR images, the predictions of currents and the atmospheric pressure in the western Mediterranean demonstrate the relationship existing between the location of the internal wave and the phase of surface tidal current, suggest that this relationship is sufficiently robust to allow general forecasting of the manifestation of HAIWs in the Strait (Vázquez et al., 2008). Hence, the typical 
sequence of HAIWs generation and propagation in the Strait is; generation of trapped waves above the Camarinal Sill when the westward flow velocity is $>1 \mathrm{~m} / \mathrm{s}$, displacement of the trapped waves towards the east of the Sill at slack water, and propagation of wave trains towards the east after the peak in westward tidal flow. Therefore, the empirical model (Vázquez et al., 2008) based on the predictions of barotropic tidal current over the Camarinal Sill may be capable of predicting the time when HAIWs are generated, and the time when they will be released and propagated towards the Alboran Sea.

\subsection{High spatial resolution analysis of the internal waves.}

The origin of the surface signatures associated with HAIWs is the modulation of surface-wave spectra (Alpers, 1985). Roughness variations are caused by the creation of convergent (rough) and divergent (smooth) zones set up by the internal wave currents that move across the surface in phase with wave's subsurface crests and troughs (Munk et al., 2000; Jackson 2007). Changes in surface roughness modify reflectance and water leaving radiance (Cox and Munk, 1954; Frouin et al., 1996; Gordon and Voss, 1999). In the case of optical images, which rely on sunlight, surface signals maybe caused by the effects of surface roughness on diffuse reflection-transmittance at the surface, surface waves breaking (white-capping) or sunglint, i.e., specular reflection, prevalent in images where the sum of the incidence zenith angle and solar zenith angle is $\sim 90$ (Mitnik et al. 2000). In both of the S2A examples (Fig.4), sunglint is not expected to be important, suggesting the principal effect of the rough and smooth zones is on diffused reflectancetransmittance. Here, similar to SAR images, rough zones are expected to be brighter as light is scattered towards the sensor, and vice-versa for smooth zones (Mitnik et al., 2000). Strong enhancement of brightness is expected when surface waves begin to break, creating whitecaps with highly reflective foam. 
On 8 March 2016 at 11:20 UTC (Fig. 4a) and 7 April 2016 at 11:12 UTC (Fig. 4b), internal wave activity was observed in S2A images in different areas of the Strait of Gibraltar, including Algeciras Bay. The images suggested internal solitary wave packets consisting of more than 10 long internal waves in the Alboran Sea.
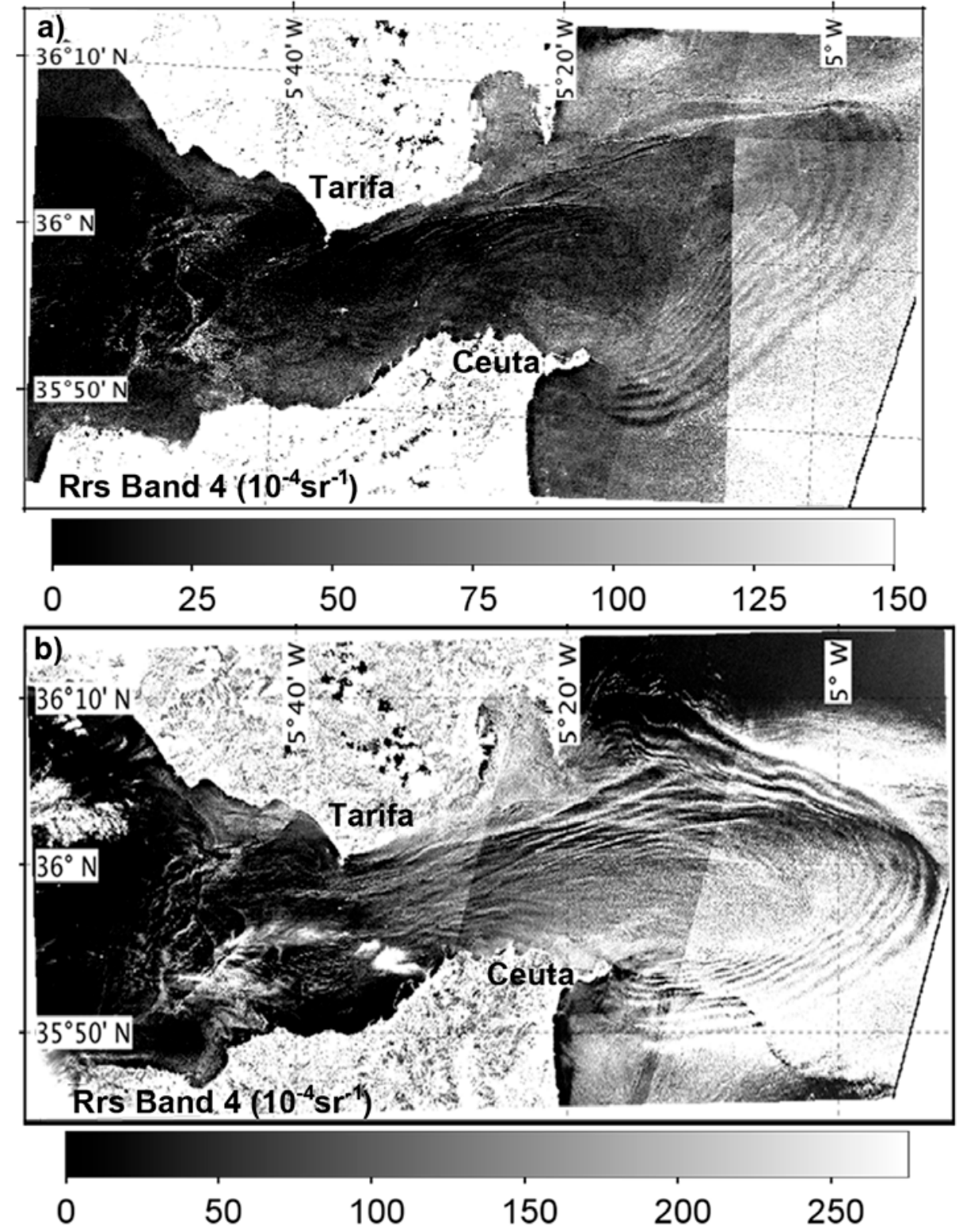

Fig. 4. S2A reflectance distribution at $665 \mathrm{~nm}$ (band 4, $10 \mathrm{~m}$ spatial resolution) showing the internal waves in several places. a) Image captured on 8 March 2016. b) Image captured on 7 April 2016. 
The tidal current prediction (Fig. 5) indicates that, at the time when the S2A images were acquired, the tide currents were at their maximum flowing out towards the Atlantic Ocean (-1.8 and -2 m/s, for 8 March and 7 April 2016, respectively, Fig. 5). According to the empirical method proposed by Vázquez et al. (2008), on this occasion the waves should have begun to be generated at about 09:00 UTC on the Camarinal Sill. However, the internal waves observed in the Alboran Sea must have been generated in the previous tidal cycle, when the tidal velocity towards the Atlantic was around $-1 \mathrm{~m} / \mathrm{s}$ (Fig. 5, around 22 UTC on 7 March and 6 April 2016, respectively), and start to move toward Mediterranean Sea around 23:00 UTC on 7 March and 6 April 2016, respectively (Fig. 5).

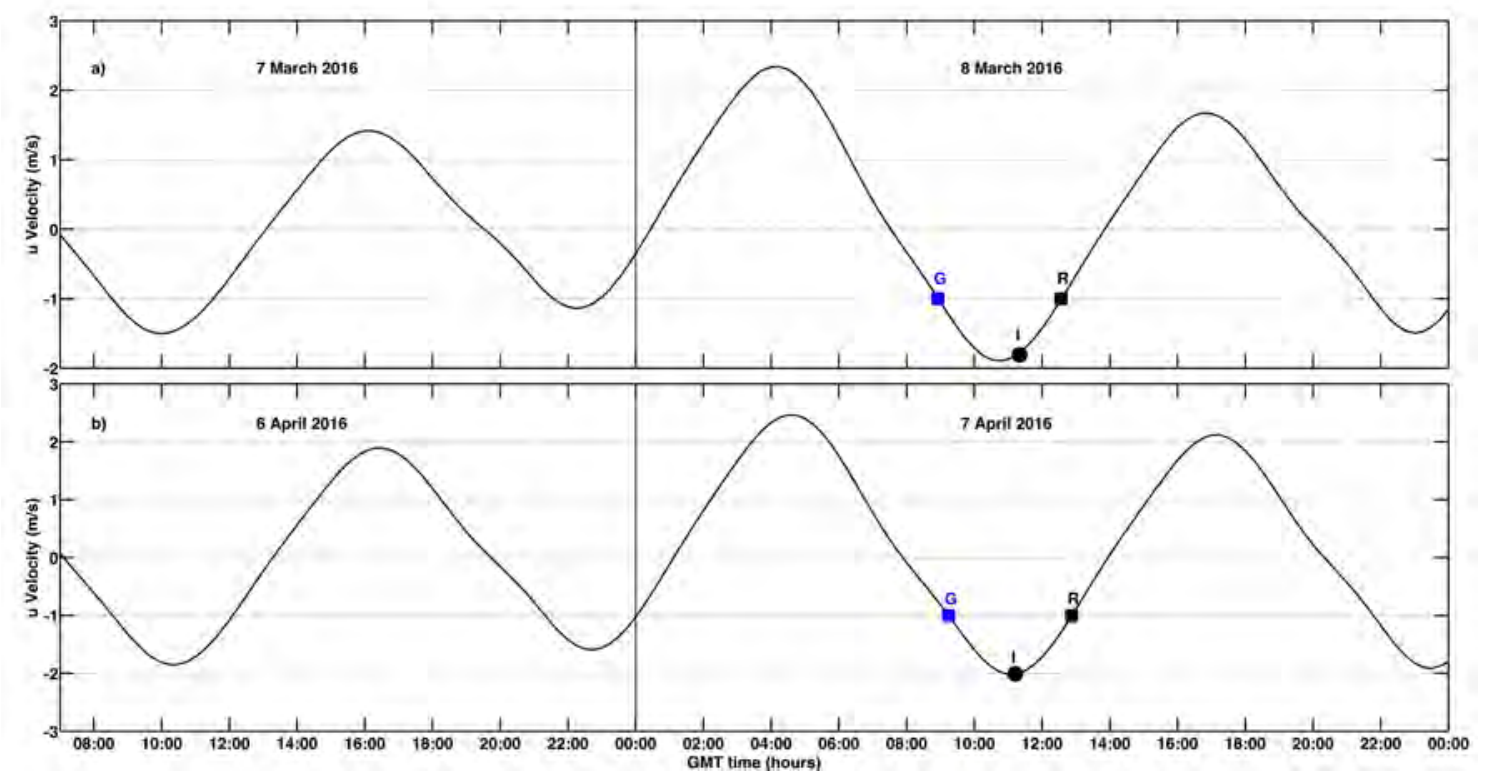

Fig. 5. Two days of predicted barotophic tidal current over the Camarinal Sill for a) 7- 8 March 2016 and b) 6 - 7 April 2016. The blue and black squares indicate the time when the HAIWs were generated $(\mathrm{G})$ and released $(\mathrm{R})$, respectively. The black dot indicated the time when the S2A image was captured (I).

The high spatial resolution of the S2A images $(10 \mathrm{~m})$ allows us to analyse the spatial features of this internal wave activity in several places of the Strait of Gibraltar. 
Specifically, Fig. 6 shows the generation of internal waves in the Camarinal Sill. These images show a curvilinear structure that corresponds to the crest of the internal waves. This form is very persistent in time, being present in both the SAR images (Fig. 2a) and S2A images (Fig. 6).
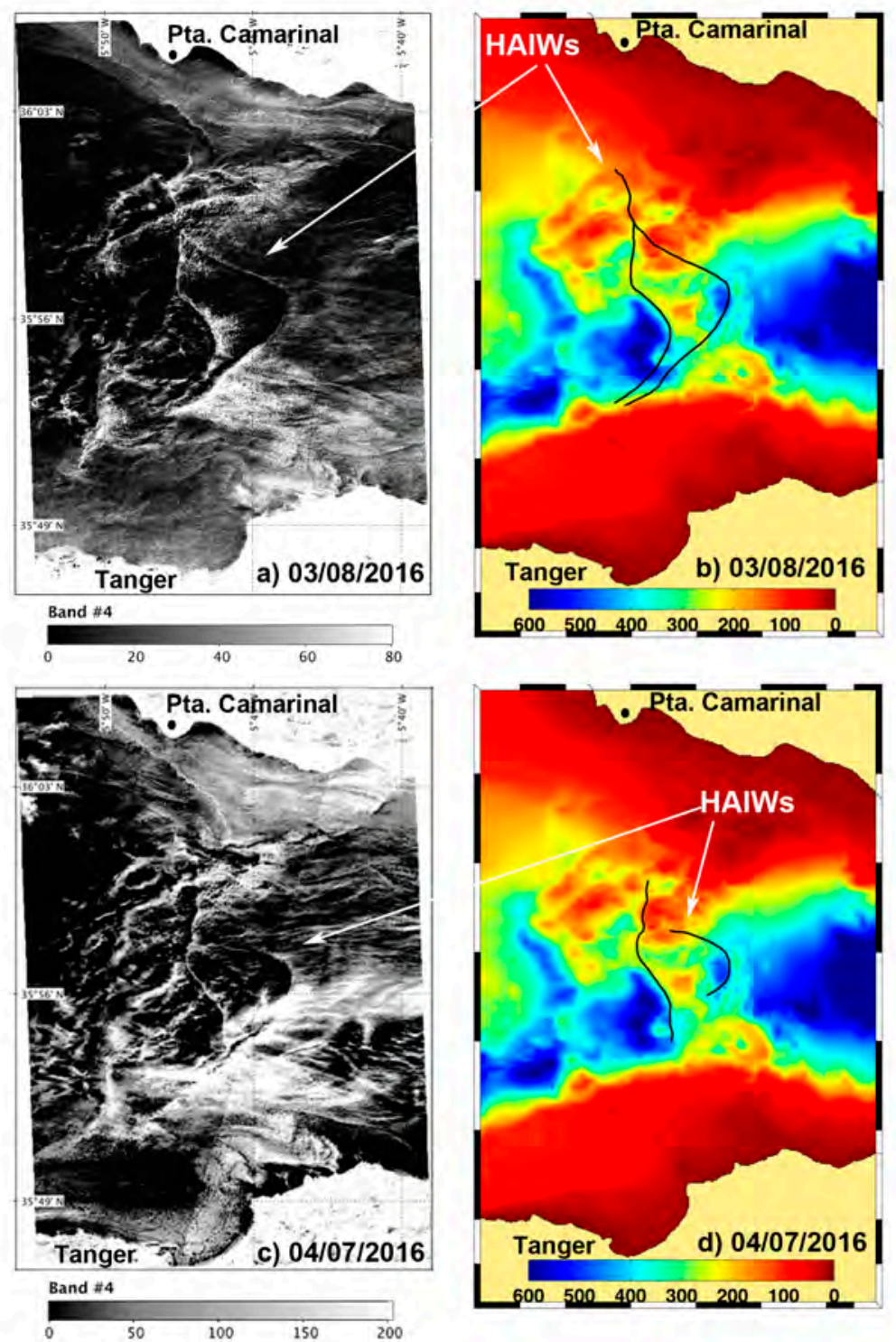

Fig. 6. S2A reflectance distribution at $665 \mathrm{~nm}$ (Band $4,10^{4} 1 / \mathrm{sr}$ ) showing the internal waves in Camarinal Sill. a) Image captured on 8 March 2016. c) Image captured on 7 April 2016. Images b) and d) shows the bathymetry (in m) of the Strait of Gibraltar where the internal wave fronts are overlaid (black lines). 
As noted previously, critical and supercritical conditions are reached when the Froude number is $>=-1$, meaning that the velocity of the barotropic flow is equal to (or greater than) the linear phase speed of the generated internal wave. In these conditions, the westflowing barotropic flow is larger than the eastward internal wave velocity, so HAIWs remain "arrested" and grow in intensity. In the Strait, these hydraulical conditions are generated by the strong flow towards the Atlantic Ocean, with tidal currents and subinertical flow (principally due to atmospheric pressure over Alboran Sea) of greater than $1 \mathrm{~m} / \mathrm{s}$ (Vázquez et al., 2008). These critical or supercritical conditions favour the trapping and amplification of the HAIWs, which grow by harvesting kinetic energy at the lee side of the sill (Farmer and Armi, 1988; Nakamura and Awaji, 2001; Vlasenko et al., 2005). The high intensity of the batrotropic flow towards the Atlantic is not able to separate the internal waves from the lee side of the sill. This is because that, although conditions over the sill were critical or supercritical, downstream of the sill the flow decelerates, leading to subcritical conditions which allow the internal waves to stand trapped on the eastern flank of the sill. The HAIWs trapped by the bathymetry are clearly detected in Fig. 6. As a consequence of the trapping mechanism, the internal wave is continuously growing, with higher amplitudes and accumulating more energy, but as it is trapped by the flow over an abrupt bathymetry, it could not move towards the Mediterranean Sea. While the internal waves stand trapped, a convergence front is created between the valley and crest of the internal wave just between the valley and crest of the bathymetry. This convergence front can be detected in SAR images (Fig. 2a and 2c) due to the roughness of the surface water and by optical images (Fig. 6) due to accumulated material in the surface water (Macías et al., 2010), or changes in the remote sensing reflectance due to roughness (Novoa et al., 2015). 
Fig. 7 shows internal waves in the Algeciras Bay and lateral bands south of Gibraltar that can also be detected in the image of 7 April 2016 (Fig. 4b). These types of fronts were previously reported by Watson and Robinson (1990) and Richez (1994) using radar images. The surface signals are not as intense or frequent as HAIWs generated on the Camarinal Sill, and their effects on the hydrodynamic and biogeochemical conditions of the Strait of Gibraltar are probably minor. Analysing data from the shore radar located at Gibraltar, Watson and Robinson (1990) identified two types of internal waves signals. One from the refraction of HAIWs from the Camarinal Sill during their propagation towards the Mediterranean Sea (A-waves) and a second type deriving from the northeast, almost parallel to the strait axis (O-waves). The images from S2A (Fig. 4) show a longitudinal signal from Tarifa extending into the Alboran Sea, its direction and size coinciding with the abrupt bathymetry between the north coast and the central channel in the same area (Fig. 7). There are not enough data to discuss the origin of these HAIWs, but they appear similar to the O-waves described by Watson and Robinson (1990). In the oriental area of the Strait of Gibraltar, the mean position of the interface is parallel to isobars and it deepens from north $(\sim 80 \mathrm{~m})$ to south ( $\sim 120 \mathrm{~m})$ (Bray et al., 1990). Probably, the signal of the internal waves in the remote sensing images was more intense in the north than in the south side due to the shallower position of the interface.

Inside Algeciras Bay, several internal waves can be observed (Fig. 7a). Numerical simulations and in-situ data suggest that these are a consequence of refraction of HAIWs generated on the Camarinal Sill as they propagate toward the Mediterranean Sea (Álvarez et al., 2011; Chioua et al., 2013). In this case, probably the waves related to the image acquired on 8 March 2016 at 11:20 UTC (Fig. 7a) were generated at around 21:00 UTC and released about 23:00 UTC on 7 March 2016 from the Camarinal Sill 
(Fig. 5a). It is interesting to observe that the propagation pathways of the surface signal of these internal waves changes slightly, matching the orientation of the main axis of the Algeciras canyon, as is expected for the development of non-linear processes (increasing amplitude and energy) during interaction with shallow topography. This feature has also been found in other canyons, such as Nazaré (Muacho et al., 2013) and Portimao (Bruno et al., 2006).

Unfortunately, there are no HICO images that have been captured with HAIWs within the Algeciras Bay, although it is a frequently recurring phenomenon (Chioua et al., 2013), and therefore we cannot establish its relationship with chlorophyll patterns. However, the presence of HAIWs in the bay generates vertical mixing processes (Chioua et al., 2013) and therefore the biogeochemical features could be affected.
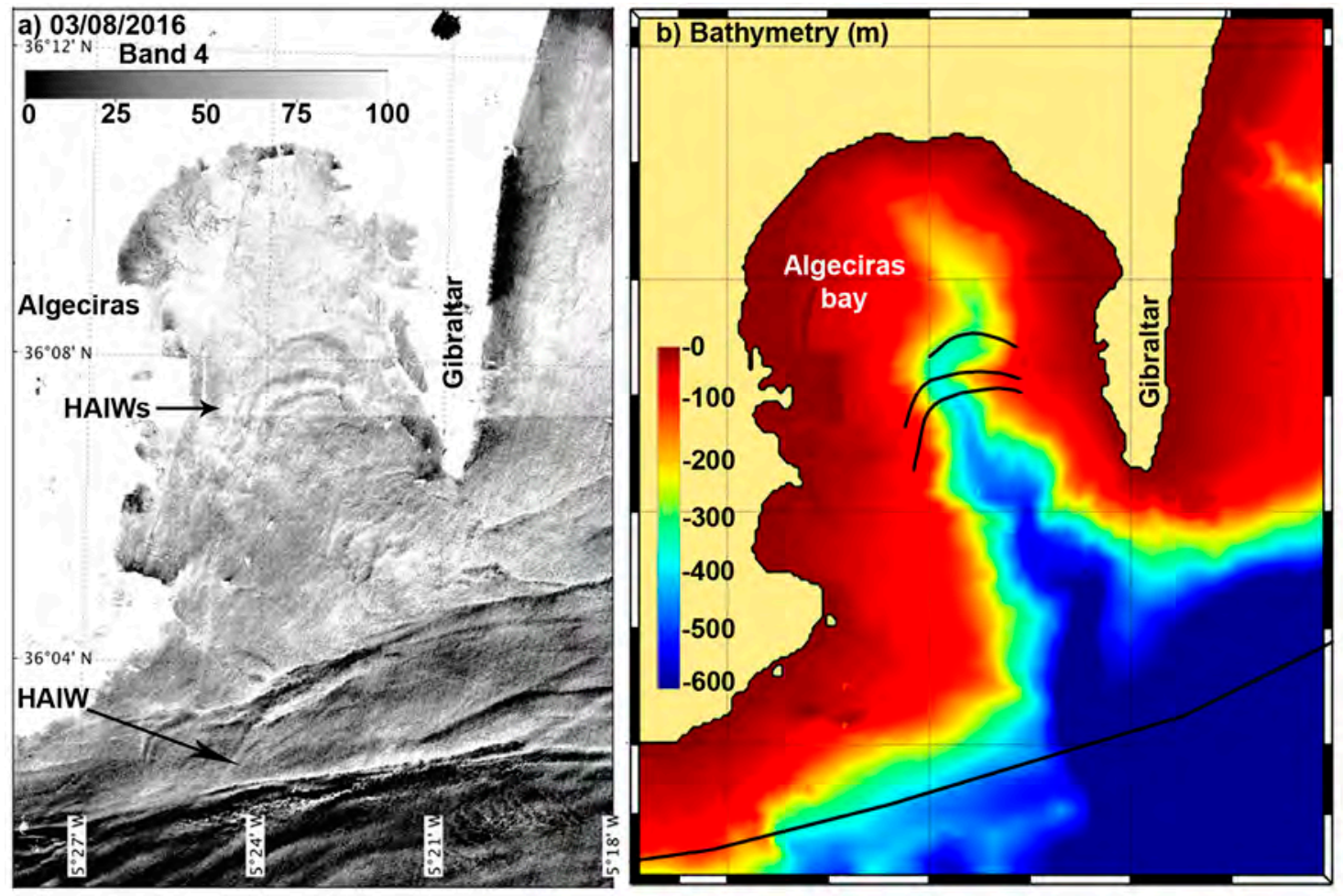

Fig. 7. a) S2A reflectance distribution at $665 \mathrm{~nm}$ (Band 4, 10 $0^{-1} / \mathrm{sr}$ ) showing the internal waves in Algeciras Bay on 8March 2016. b) Bathymetry (in m) of the Algeciras Bay where the internal wave fronts are overlaid (black lines). 
Finally to the east, the S2A images (Fig. 4) show how the internal waves in the Alboran Sea disintegrate into wave trains of 7 to 10 solitons, which have an impact on the biogeochemistry of the Alboran Sea (Macías et al., 2008; Vazquez et al., 2009; Bartual et al., 2011).

\subsection{Biogeochemical patterns of internal waves.}

Once analysed the distribution of the internal waves and its relationship with the tidal dynamics, the use of hyperspectral images allows us to investigate the biogeochemical patterns of the HAIWs in the Strait. Fig. 8 illustrates a sequence of HICO images and their corresponding tidal current prediction. The first HICO image (Fig. 8a, 5 December 2009 at 14:39 UTC), collected just after the maximum westward tidal flow $(2 \mathrm{~m} / \mathrm{s}$, Fig. $8 \mathrm{~b}$ ), shows the surface radiance ( $\mathrm{Lt}$ at $644 \mathrm{~nm}$ ) signal. The structure and position is comparable to the two roughness fronts observed in Fig. 2a. The next HICO image (Fig. 8c, 25 September 2011 at 10:44 UTC) was acquired 2 hours before slack water with low flow velocities (Fig. 8d), comparable to the situation representing the displacement of the arrested waves to the east. Again Lt at $644 \mathrm{~nm}$ reveals a structure quite similar to the roughness fronts detected by the SAR image (Fig. 2c). The last HICO image (Fig.e 8e, 4 November 2010 at 15:24 UTC) acquired when eastward tidal flow was at its maximum (Fig. 8f) represents an oceanographic situation similar to the example showing propagation of wave trains towards the Mediterranean Sea after the peak in westward tidal flow (Fig. 2e and 2g). Harmonic tidal current predictions suggested that westward tidal flow was intense enough to generate HAIWs over the Sill at around 09:00 UTC (Fig. 8f). These were arrested until the flow reduced at around 11:00 UTC (5 hours before HICO image was acquired) and began to propagate and disintegrate as a train of internal waves moving towards the Mediterranean Sea. Although not as clearly defined as the wave train shown in Fig. 2e, 
this suggests that the structures in the HICO image represent the signal of the HAIWs travelling east. Hence, this sequence of HICO images provides a reasonable example of the major dynamics of HAIWs generated by flow over the Camarinal Sill in the Strait of Gibraltar. Different values of $\mathrm{Lt}$ at $644 \mathrm{~nm}$ are also likely to be related to the modification of the water leaving radiance due to surface roughness and whitecaps caused by internal wave activity (Gordon and Voss, 1999; Klemas, 2012).

\section{a) $12 / 05 / 2009$}
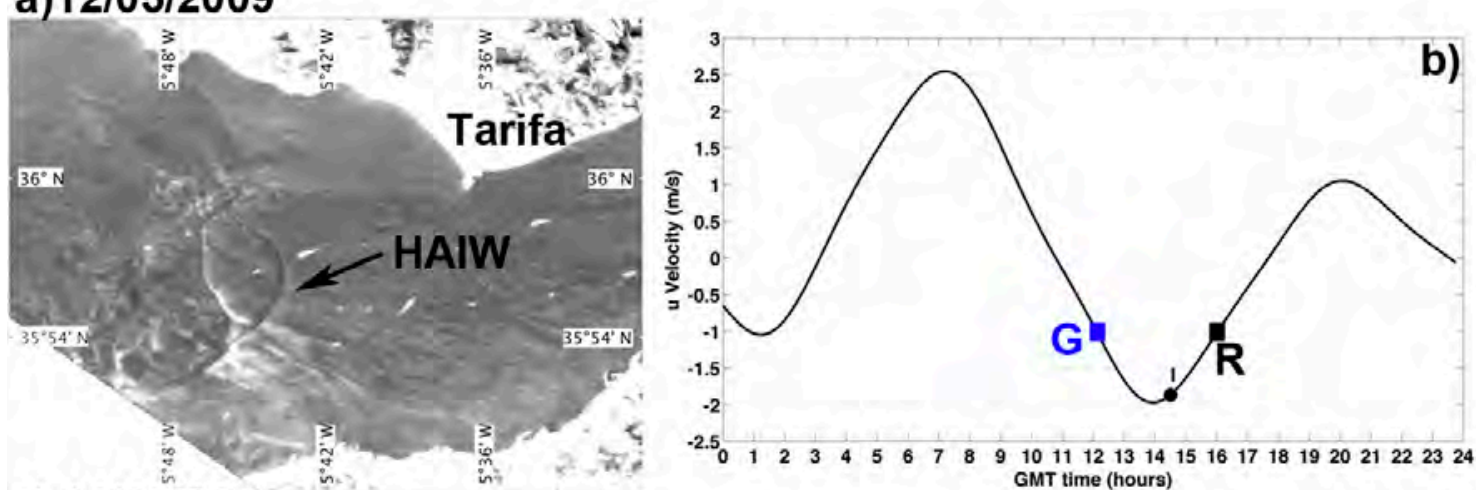

\section{c) $11 / 25 / 2011$}
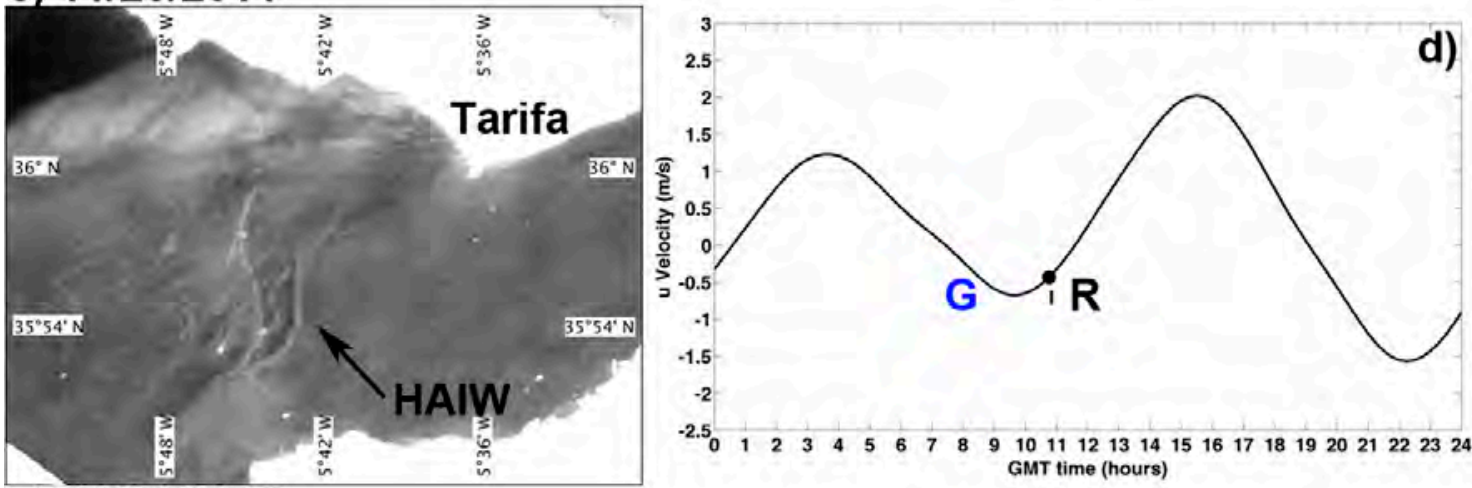

\section{e) $11 / 04 / 2010$}
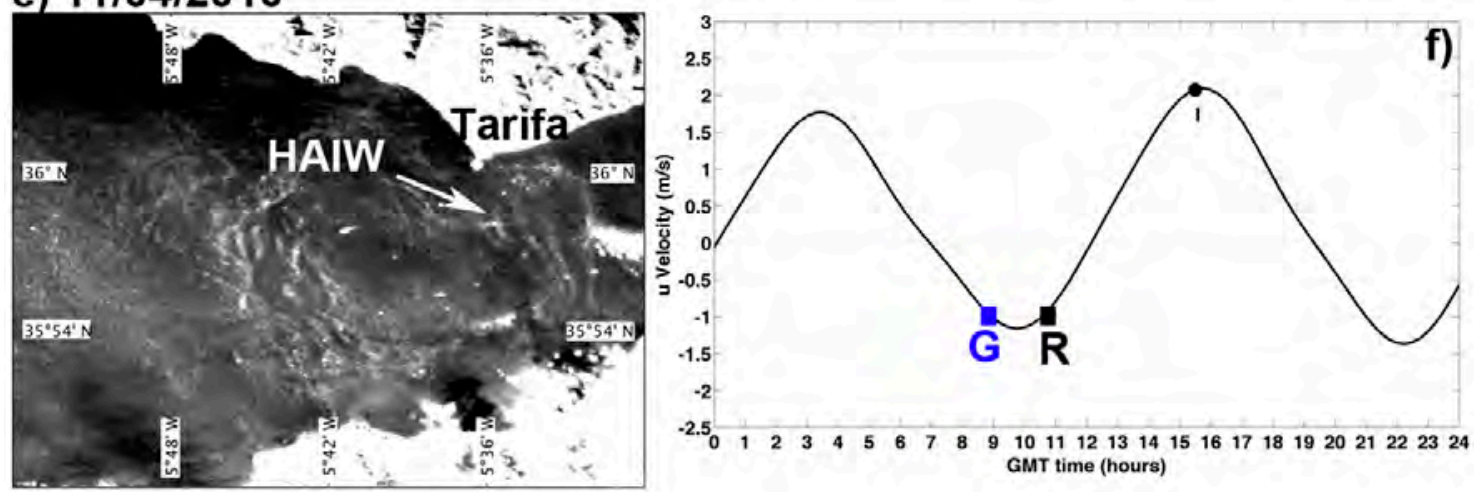

Fig. 8. HICO images showing the distribution of $\mathrm{Lt}$ at $644 \mathrm{~nm}$ corresponding to: a) 5 December 2009; c) 25 September 2011; and e) 4 November 2010. Each HICO image is accompanied by current tidal prediction (b, $d$, and $\mathrm{f}$ ). The blue and black squares 
indicate the time when the HAIWs were generated $(\mathrm{G})$ and released (R), respectively. The black dot indicates the time when the HICO image was captured (I).

Fig. 9 shows the chlorophyll patterns from HICO images related to the two days considered. Chlorophyll concentrations $\left(0.3\right.$ to $\left.1 \mathrm{mg} / \mathrm{m}^{3}\right)$, derived by applying the recently developed algorithm specific for the Alboran Sea, ALBOC3 (Gómez-Jakobsen et al., 2016), varied within the typical range for the region $\left(0.1\right.$ to $\left.3.5 \mathrm{mg} / \mathrm{m}^{3}\right)$ (Macías et al., 2006; Vázquez et al., 2009). Chlorophyll concentrations were highest along the coasts (coastal enrichment, Macias et al., 2006; Ramírez-Romero et al., 2012) and showed band-like structure in the vicinity of the internal waves, with values appearing to be higher at the crest of the internal waves in comparison with nearby waters (Fig. 9). Chlorophyll concentrations had local maximums very similar to the bands of varying roughness observed in the SAR images, suggesting a common cause: internal waves (Fig. 9).

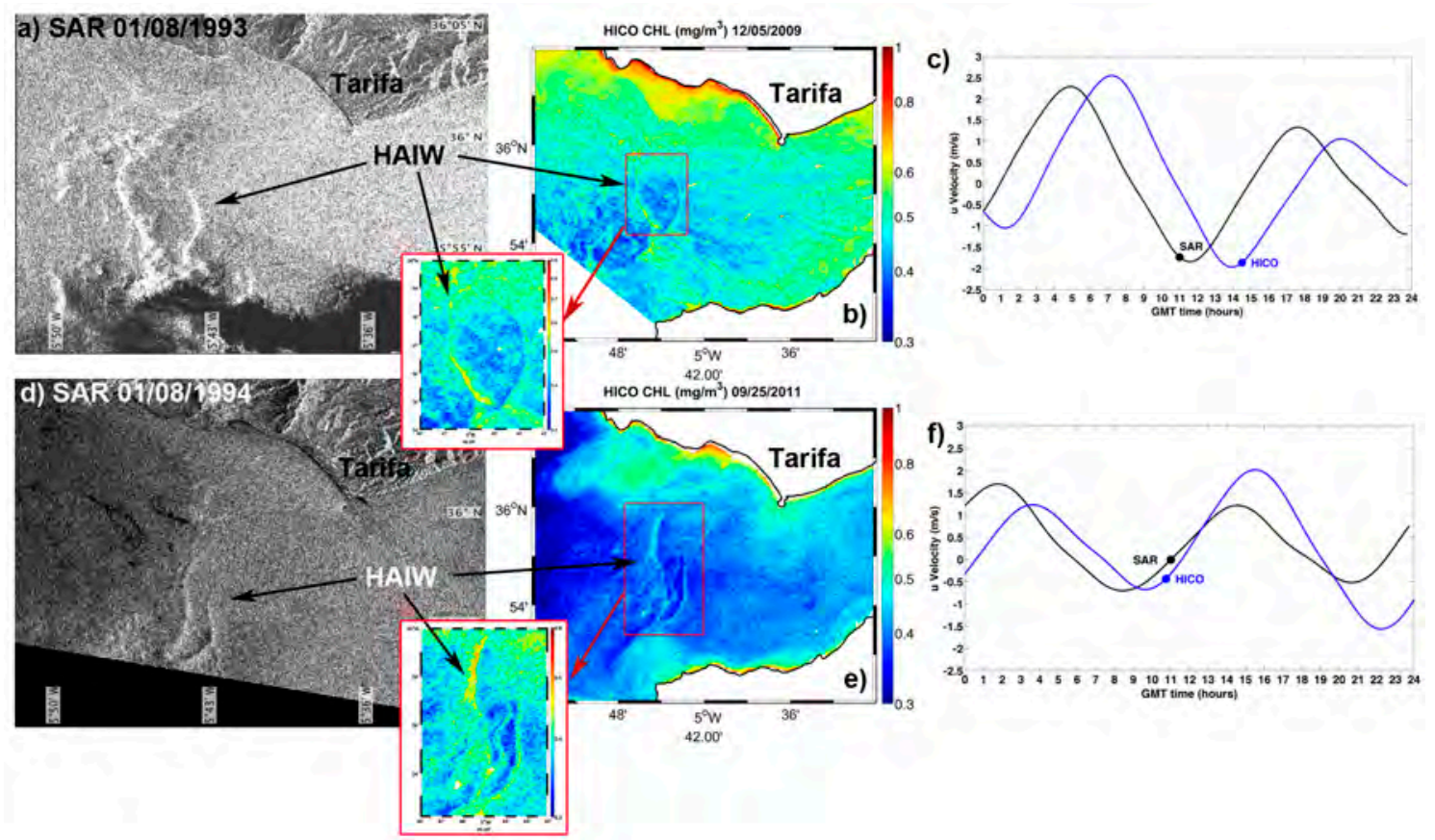

Fig. 9. SAR images (a and d) showing the position of HAIWs. HICO images showing the distribution of chlorophyll concentration (CHL) using ALBOC3 algorithm (in 
$\mathrm{mg} / \mathrm{m}^{3}$ ), for images captured at (b) 5 December 2009 and (e) 25 September 2011. Each SAR and HICO image is accompanied by current tidal prediction (c and f).

In other areas such as the South China Sea (Wang et al., 2007) and Bay of Biscay (Da Silva et al., 2002), increased chlorophyll concentrations observed at the internal waves train are mainly due to uplifting of deep chlorophyll maximums along the passage of the internal tidal crest. However, the increase of chlorophyll in the crest of the internal waves observed in Camarinal Sill (Fig. 9) seem to be mostly related with the accumulation of the phytoplankton cells (Macías et al., 2010). Internal waves displace the pycnocline/thermocline vertically and generate internal currents that converge and diverge on the surface, capturing phytoplankton cells and zooplankton (Macías et al., 2010). Also, the pulsating presence of the different types of water masses throughout the tidal cycle conditions the presence of different chlorophyll maxima associated with specific water interfaces (Macías et al., 2008; Bartual et al., 2011). Still it should be noted that this physical mechanism also modulates sea surface roughness. This implies variations in water leaving radiance that may affect the retrieval of inherent optical properties, i.e., chlorophyll; therefore to some extent these patterns may be simply in part due to changes in roughness (Fig. 9).

So far, from using medium-resolution images (i.e., chlorophyll products from MERIS and MODIS), it was not possible to capture the detailed biogeochemical properties associated with internal waves. HICO demonstrates the potential advantage of high-resolution, hyperspectral mapping of chlorophyll dynamics. Fig. 10 displays the distribution of chlorophyll concentration during the same day (4 November 2010) in the Strait of Gibraltar using different sensors (MERIS, MODIS and HICO). Each image was acquired at a different time and thus tidal phase; the MERIS image (Fig. 10a) was 
acquired after HAIW generation at the very beginning of the internal wave release (Fig. 10d). During this phase, high chlorophyll along the coastal edges (north and south of the Camarinal Sill) is advected towards the centre of the channel (Macías et al., 2008, Vázquez et al., 2009). The development of this process is evident in the MODIS image (Fig. 10b) acquired 2 hours later, just after slack water (Fig. 10d). In comparison to Fig. $9 \mathrm{~b}$, which represents very similar hydraulic conditions, the HICO image is capable of revealing both these coastal maximums and the narrow, intense local maximums associated with internal waves in the centre of the channel. The final HICO image in the series (Fig. 10c), collected almost 3 hours later, at the peak of westward tidal flow (Fig. 10d), shows the local maximums (up to $30 \%$ ) in chlorophyll concentration associated with the internal waves train travelling eastwards through the Tarifa Narrow (Fig. 10c). Hence, the enhanced spatial and spectral resolution provided by sensors like HICO can provide a deeper understanding about the biogeochemical patterns associated with internal waves. This increase of chlorophyll is also found in other areas such as Nazare Canyon (Muacho et al., 2013), where chlorophyll concentration varied $\sim 0.2 \mathrm{mg} / \mathrm{m}^{3}$ along the internal wave propagation direction, which represents an enhancement of more than $50 \%$ compared with background regions unaffected by the internal waves. 

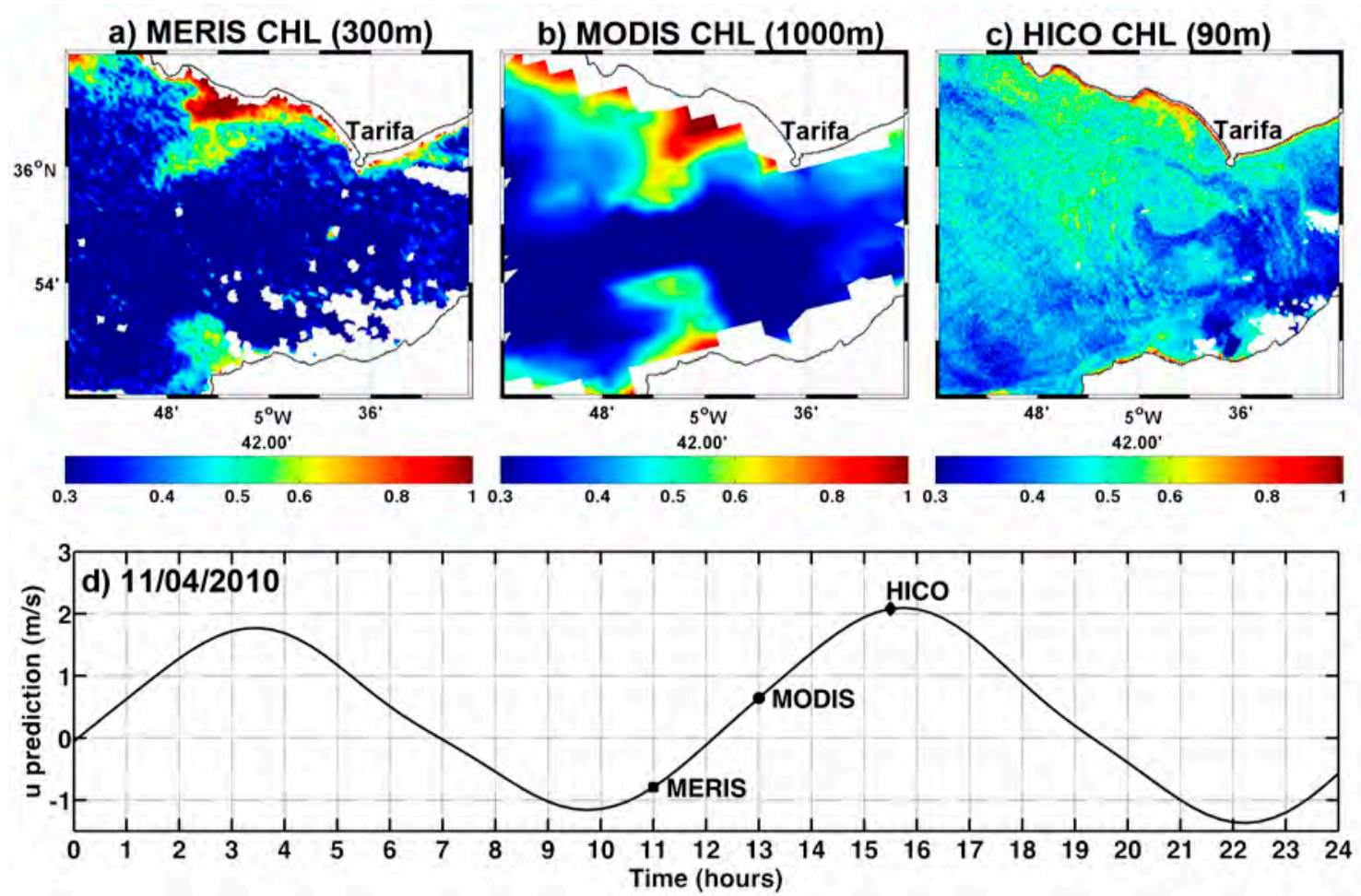

Fig. 10. Chlorophyll (in $\mathrm{mg} / \mathrm{m}^{3}$ ) surface distribution on 4 November 2010 captured by a) MERIS, b) MODIS, and c) HICO. d) Current tidal prediction for 4 November 2010. Dots indicate the time of capture of images.

\section{Conclusions.}

In the present work we used high spatial resolution images from Sentinel-2 and hyperspectral images from HICO to study the relationship between physical and biogeochemical processes associated with internal waves dynamics in the Strait of Gibraltar. Several HICO and Sentinel-2 images have been processed to provide remote sensing reflectance. These were assessed in the context of other available remote sensing data (such as medium resolution ocean colour and radar images) and previous studies, to identify the ocean colour characteristics of internal waves in the Strait of Gibraltar while they stand arrested around the Camarinal Sill, the main region of HAIWs generation. In addition, several solitons were analysed in the Algeciras Bay and Alboran Sea. The analysed results demonstrate the value of high spectral and high 
spatial resolution sensors for retrieving the detailed structure of surface water constituents in regions of internal wave generation and propagation, such as the Strait of Gibraltar and the Algeciras Bay. This enhanced spatial and spectral resolution revealed the detailed biogeochemical patterns associated with the internal waves and suggests local enhancements of productivity associated with the internal waves train. Hence, this study represents a precursor to work with other hyperspectral sensors in the future, such as HyspIRI or EnMAP, to analyse HAIWs in the Strait of Gibraltar.

HAIWs provide an important mechanism that enhances vertical mixing, increasing nutrient supply and phytoplankton accumulation in the surface layer of oceans. Furthermore, convergence and divergence zones related to the dynamics of internal waves lead to the accumulation of organic surface films, phytoplankton, and zooplankton (Macías et al., 2010), generating horizontal structure in the otherwise relatively homogeneous surface oceans. These processes mean that internal waves are an important factor in determining local biological productivity, as well as the transport of plankton and fish larvae (Holligan, et al, 1985).

\section{Acknowledgments.}

We would like to thank the OceanColor website for providing the HICO, MERIS and MODIS images. Sentinel-2 images were obtained from the Copernicus Programme. SAR images were obtained from the European Space Agency (ESA) under the Cat-1 project (C1P.14501). Atmospheric pressure data were downloaded from ERAInterim of ECMWF web site. Aerosol optical thickness data were obtained from the AERONET stations of Huelva and Málaga. We extend our thank the reviewers for their valuable comments which helped to improve the manuscript. This study was supported 
by the Spanish National Project (CTM2014-58181-R), MEGAN (CTM2013-49048-C22-R), Regional project (PR11-RNM-7722), and PIE (201530I012).

\section{References.}

Alpers, W. 1985. Theory of radar imaging of internal waves. Nature, 314, 245-247, doi:10.1038/314245a0.

Alpers, W., Brandt, P., Rubino, A. 2008. Internal waves generated in the Straits of Gibraltar and Messina: observations from space. In: Remote sensing of the European Seas, Springer Netherlands, 319-330, doi: 10.1007/978-1-4020-6772324.

Álvarez, Ó., González, C. J., Mañanes, R., López, L., Bruno, M., Izquierdo, A., GómezEnri, J., Forero, M. 2011. Analysis of short-period internal waves using waveinduced surface displacement: A three-dimensional model approach in Algeciras Bay and the Strait of Gibraltar. Journal of Geophysical Research: Oceans, 116, C12, doi: 10.1029/2011JC007393.

Armi, L., Farmer, D. 1988. The flow of Mediterranean Water through the Strait of Gibraltar. Progress in Oceanography, 21(1), 1-105, doi: 10.1016/0079$6611(88) 90055-9$.

Bartual, A., Macías, D., Gutierrez-Rodriguez, A., García C.M., Echevarría, F. 2011. Transient pulses of primary production generated by undulatory processes in the western sector of the Strait of Gibraltar. Journal of Marine Systems, 87(1), 25-36, doi: http://dx.doi.org/10.1016/j.jmarsys.2011.02.021.

Berger, M., Moreno, J., Johannessen, A.J., Levelt, F.P., Hanssen, F.R. 2012. ESA‘s Sentinel missions in support of earth system science. Remote Sensing of Environment, 120, 84-90, doi: http://dx.doi.org/10.1016/j.rse.2011.07.023. 
Berk, G.P., Anderson, P.K., Acharya, L.S., Bernstein, L., Muratov, J., Lee, M., Fox, S.M., Adler-Golden, J.H., Chetwynd, M.L., Hoke, R.B., Lockwood, J.A., Gardner, T.W., Cooley, C.C., Borel, P.E., Lewis, E.P. 2006. MODTRANTM5: 2006 update. In: Proceedings of SPIE-The International Society for Optical Engineering, pp. 6233, doi: 10.1117/12.665077.

Bray, N.A., Winant, C.D., Kinder, T.H., Candela, J. 1990. Generation and kinematics of the internal tide in the Strait of Gibraltar. In: The Physical Oceanography of Sea Straits, L. J. Pratt, Kluwer Academic Publishers, Netherlands, 477-491, doi: 10.1007/978-94-009-0677-8_23.

Bruno, M., Alonso, J.J., Cózar, A., Vidal, J., Ruiz-Cañavate, A., Echevarría, F., Ruiz, J. 2002. The boiling-water phenomena at Camarinal Sill, the Strait of Gibraltar. Deep Sea Research Part II, 49(19), 4097-4113, doi: http://dx.doi.org/10.1016/S0967-0645(02)00144-3.

Bruno, M., Chioua, J., Romero, J., Vázquez, A., Macías, D., García, C. M., Ramírez, E., Echevarría, F., Reyes J. 2013. The importance of sub-mesoscale processes for the exchange of properties through the Strait of Gibraltar. Proress in Oceanography, 116, 66-79, doi: 10.1016/j.pocean.2013.06.006.

Bruno, M., Vázquez, A., Gómez-Enri, J., Vargas, J.M., García-Lafuente, J., RuizCañavate, A., Mariscal, L., Vidal, J. 2006. Observations of internal waves and associated mixing phenomena in the Portimao Canyon area. Deep Sea Research Part II: Topical Studies in Oceanography, 53(11), 1219-1240, doi: http://dx.doi.org/10.1016/j.dsr2.2006.04.015.

Candela, J., Winant, C., Bryden, H.L. 1989. Meteorologically forced subinertial flows through the Strait of Gibraltar. Journal of Geophysical Research: Oceans, 94(C9), 12667-12679, doi: 10.1029/JC094iC09p12667. 
Chioua, J., Bruno, M., Vázquez, A., Reyes, M., Gomiz, J. J., Mañanes, R., Alvarez, O., González, C., Lopez, L., Gomez-Enri, J. 2013. Internal waves in the Strait of Gibraltar and their role in the vertical mixing processes within the Bay of Algeciras. Estuarine, Coastal and Shelf Science, 126, 70-86, doi: http://dx.doi.org/10.1016/j.ecss.2013.04.010.

Chioua, J., Dastis, C., González, C.J., Reyes, E., Mañanes, R., Ruiz, M.I., Álvarez, E., Yanguas, Romero, J., Álvarez, O., Bruno, M., 2017. Water exchange between Algeciras Bay and the Strait of Gibraltar: A study based on HF coastal radar. Estuar. Coast. Shelf Sci. doi:10.1016/j.ecss.2017.06.030

Corson, M.R., Davis C.O. 2011. A new view of coastal oceans from the space station. Eos, Transactions American Geophysical Union, 92(19), 161-162, doi: 10.1029/2011EO190001.

Cox, C., Munk, W. 1954. Measurement of the roughness of the sea surface from photographs of the sun's glitter. Journa of the Optical Society of America, 44, 11, 838-850.

Da Silva, J.C.B., New, A.L., Srokosz, M.A., Smyth, T.J. 2002. On the observability of internal tidal waves in remotely-sensed ocean colour data. Geophysical Research Letters, 29(12), 1569, doi: 10.1029/2001GL013888.

Dierssen, H., McManus, G.B., Chlus, A., Qiu, D., Gao, B.C., Lin, S. 2015. Space station image captures a red tide ciliate bloom at high spectral and spatial resolution. Proceedings of the National Academy of Sciences, 112(48), 1478314787, doi: 10.1073/pnas.1512538112.

Drusch, M., Del Bello, U., Carlier, S., Colin, O., Fernandez, V., Gascon, F., Hoersch, B., Isola, C., Laberinti, P., Martimort, P., Meygret, A., Spoto, F., Sy, O., Marchese, F., Bargellini, P. 2012. Sentinel-2: ESA's Optical High-Resolution 
Mission for GMES Operational Services. Remote Sensing of Environment, 120, 25-36, doi: http://dx.doi.org/10.1016/j.rse.2011.11.026.

Farmer, D.M., Armi, L. 1988. The flow of Mediterranean water through the Strait of Gibraltar. Progress in Oceanography, 21(1), 1-105, doi: 10.1016/00796611(88)90055-9.

Flecha, S., Pérez, F.F., García-Lafuente, J., Sammartino, S., Ríos, A.F., Huertas, I.E. 2015. Trends of $\mathrm{pH}$ decrease in the Mediterranean Sea through high frequency observational data: indication of ocean acidification in the basin. Scientific Reports, 5, 16770, doi: 10.1038/srep16770.

Frouin, R., Schwindling, M., Deschamps, P. Y. 1996. Spectral reflectance of sea foam in the visible and near-infrared: In-situ measurements and implications for remote sensing of ocean color and aerosols. Journal Geophysical Research: Oceans, 101(C6) 14361-14371, doi: 10.1029/96JC00629.

Gil, J. 2006. Biología y pesca del voraz Pagellus bogaraveo (Brünnich, 1768) en el estrecho de Gibraltar. PhD Tesis. University of Cadiz.

Gitelson, A., Gao, B.C., Li, R.R., Berdnikov, S., Saprygin, V. 2011. Estimation of chlorophyll-a concentration in productive turbid waters using a Hyperspectral Imager for the Coastal Ocean - the Azov Sea case study. Environmental Research Letters, 6(2), 024023, doi: http://dx.doi.org/10.1088/1748-9326/6/2/024023.

Gómez-Jakobsen, F., Mercado, J.M., Cortés, D., Ramírez, T., Salles, S., Yebra, L. 2016. A new regional algorithm for estimating chlorophyll-a in the Alboran Sea (Mediterranean Sea) from MODIS-Aqua satellite imagery. International Journal of Remote Sensing, 37(6), 1431-1444, doi: 10.1080/01431161.2016.1154223. 
Gordon, H.R., Voss, H.J. 1999. MODIS Normalized Water-leaving Radiance, Algorithm Theoretical Basis Document (MOD 18), Ref. No. ATBD-MOD-96. NASA Contract Number NAS503163.

Guanter, L., Gómez-Chova, L., Moreno, J. 2008. Coupled retrieval of aerosol optical thickness, columnar water vapor and surface reflectance maps from ENVISAT/MERIS data over land. Remote Sensing of Environment, 112(6), 2898-2913, doi: http://dx.doi.org/10.1016/j.rse.2008.02.001.

Hibiya, T. 1986. Generation mechanism of internal waves by tidal flow over a sill. Journal of Geophysical Research, 91(C6), 7697-7708, doi: 10.1029/JC091iC06p07697.

Holligan, P.M., Pingree, R.D., Mardell, G.T. 1985. Oceanic solitons, nutrient pulse and phytoplankton growth. Nature, 314, 348-350, doi: 10.1038/314348a0.

Izquierdo, A., Tejedor, L., Sein, D.V., Backhaus, J.O., Brandt, P., Rubino, A., Kagan, B.A. 2001. Control variability and internal bore evolution in the Strait of Gibraltar: a 2-D two-layer model study. Estuarine, Coastal and Shelf Science, 53, 637-651, doi: 10.1006/ecss.2000.0706.

Jackson C. 2007 Internal wave detection using the Moderate Resolution Imaging Spectroradiometer (MODIS). Journal of Geophysical Research: Oceans, 112, doi: 10.1029/2007JC004220

Klemas, V., 2012. Remote sensing of ocean internal waves: an overview. Journal of Coastal Research, 28(3), 540-546, doi: http://dx.doi.org/10.2112/JCOASTRES-D$11-00156.1$.

Lacombe, H., Richez C. 1982. The regime of the Strait of Gibraltar. In: Hydrodynamics of Semi-enclosed Seas, Elsevier Oceanography Series, 34, 13-73. 
Lucke, R. L., Corson, M., Mc Glothlin, N. R., Butcher, S. D., Wood, D. L., Korwan, D. R.; Li, R. R., Snyder, W. A., Davis, C. O., Chen, D. T. 2011. The Hyperspectral Imager for the Coastal Ocean: instrument description and first images. Applied Optics, 50(11), 1501-1516, doi: https://doi.org/10.1364/AO.50.001501.

Macías, D., García, C.M., Echevarría, F., Vázquez, A., Bruno, M. 2006. Tidal induced variability of mixing processes on Camarinal Sill (Strait of Gibraltar): A pulsating event. Journal of Marine Systems, 60(1), 177-192, doi: http://dx.doi.org/10.1016/j.jmarsys.2005.12.003.

Macías, D., Lubián, L.M., Echevarría, F., Huertas, I.E., García, C. M. 2008. Chlorophyll maxima and water mass interfaces: Tidally induced dynamics in the Strait of Gibraltar. Deep Sea Research Par I: Oceanographic Research Papers, 55(7), 832-846, doi: http://dx.doi.org/10.1016/j.dsr.2008.03.008.

Macías, D., Martin, A.P., García, C.M., Bruno, M., García-Lafuente, J., Izquierdo, A., Vázquez, A., Yool, A., Sein, D., Echevarría, F. 2007. Analysis of mixing and biogeochemical effects induced by tides on the Atlantic-Mediterranean flow in the Strait of Gibraltar through a physical-biological coupled model. Progress in Oceanography, $\quad 74(2), \quad 252-272, \quad$ doi: http://dx.doi.org/10.1016/j.pocean.2007.04.006.

Macías, D., Garcia-Gorriz, E., Stips, A. 2016. The seasonal cycle of the Atlantic Jet dynamics in the Alboran Sea: direct atmospheric forcing versus Mediterranean thermohaline circulation. Ocean Dynamics, 66, 137-151.

Macías, D., Somavilla, R., González-Gordillo, J.I., Echevarría, F. 2010. Physical control of zooplankton distribution at the Strait of Gibraltar during an episode of internal wave generation. Mar Ecol Prog Ser, 408, 79-95. 
MacKinna, L., Garcia, R., Fearns, P. 2012. Determining inherent optical properties, bathymetry and benthic types using HICO imagery within northeast and western Australia. HICO User's Annual Report, August 2012, Remote Sensing and Satellite Research Group, Department of Imaging and Applied Physics, Curtin University.

Malenovsky, Z., Rott, H., Cihlar, J., Schaepman, E.M., Garcia-Santos, G., Fernandes, R., Berger, M. 2012. Sentinels for science: Potential of Sentinel-1, -2 , and -3 missions for scientific observations of ocean, cryosphere, and land. Remote Sensing of Environment, 120, 91-101, doi: http://dx.doi.org/10.1016/j.rse.2011.09.026.

Martimort, P., Berger, M., Carnicero, Del Bello, U., Fernandez, V., et al. 2007. Sentinel-2: The optical high-resolution mission for GMES operational services. ESA Bulletin, 131, 18-23.

Millot, C. 1999. Circulation in the western Mediterranean Sea. Journal of Marine Systems, 20(1), 423-442, doi: 10.1016/S0924-7963(98)00078-5.

Millot, C., Taupier-Letage, I. 2005. Circulation in the Mediterranean Sea. In: The Mediterranean Sea, 29-66, Springer Berlin Heidelberg, doi: 10.1007/b107143.

Mitnik, L., W. Alpers, K. S. Chen, and A. J. Chen (2000), Manifestation of internal solitary waves on ERS SAR and SPOT images: Similarties and differences, paper presented at 2000 International Geoscience and Remote Sensing Symposium (IGARSS'00), Inst. of Electr. and Electr. Eng., Honolulu. Doi: 10.1109/IGARSS.2000.858146

Morel, A., Antoine, D. 2002. Pigment Index retrieval in case 1 waters. MERIS Algorithm Theoretical Basis Document, ATBD2, 9, 25. 
Muacho, S., Da Silva, J. C. B., Brotas, V., Oliveira, P. B. 2013. Effect of internal waves on near-surface chlorophyll concentration and primary production in the Nazaré Canyon (west of the Iberian Peninsula). Deep Sea Research Part I: Oceanographic Research Papers, 81, 89-96, doi: http://dx.doi.org/10.1016/j.dsr.2013.07.012.

Munk, W., Armi, L., Fischer, K., Zachariasen, f. 2000. Spirals on the Sea, Proceedings of the Royal Society A, 456, 1217-1280.

Nakamura, T., Awaji, T. 2001. A growth mechanism for topographic internal waves generated by an oscillatory flow. Journal of Physical Oceanography, 31(8), 25112524 doi: http://dx.doi.org/10.1175/15200485(2001)031<2511:AGMFTI>2.0.CO;2.

Novoa, S., Wernand, M., van der Woerd, H. J. 2015. WACODI: A generic algorithm to derive the intrinsic color of natural waters from digital images. Limnology and Oceanography: Methods, 13(12), 697-711, doi: 10.1002/lom3.10059.

O’Reilly, J. E., Maritorena, S., Siegel, D. A., O’Brien, M. C., Toole, D., Mitchell, B. G., et al. 2000. Ocean color chlorophyll a algorithms for SeaWiFS, OC2, and OC4: Version 4. SeaWiFS postlaunch calibration and validation analyses, Part 3, 9-23, NASA/TM-2000-206892, NASA, Greenbelt, Maryland.

Pinet, P.R. 2009. Invitation to Oceanography. Sudbury, Massachusetts, Jones and Bartlett Publishers, ISBN-10: 1449648029.

Ramírez-Romero, E., Macías, D., Bruno, M., Reyes, E., Navarro, G., García, C.M. 2012. Submesoscale, tidally-induced biogeochemical patterns in the Strait of Gibraltar. Estuarine, Coastal and Shelf Science, 101, 24-32.

Ramírez-Romero, E., Macías, D., García, C.M., Bruno, M. 2014. Biogeochemical patterns in the Atlantic Inflow through the Strait of Gibraltar. Deep Sea Research Part I: Oceanographic Research Papers, 85, 88-100. 
Richez, C. 1994. Airborne synthetic aperture radar tracking of internal waves in the Strait of Gibraltar. Progress in Oceanography, 33(2), 93-159, doi: 10.1016/00796611(94)90023-X .

Ryan, J. P., Davis, C. O., Tufillaro, N. B., Kudela, R. M., Gao, B. C. 2014. Application of the hyperspectral imager for the coastal ocean to phytoplankton ecology studies in Monterey Bay, CA, USA. Remote Sensing, 6(2), 1007-1025, doi: $10.3390 / \mathrm{rs} 6021007$.

Schläpfer, D., Borel, C.C., Keller, J., Itten, K.I. 1996. Atmospheric pre-corrected diffential absorption techniques to retrieve columnar water vapour: application to AVIRIS 91/95 data. In: 6th Annual JPL Airbone Earth Science Workshop, Jet Propulsion Laboratory, Pasadena, CA, 209-217.

Szekielda, K. H., Bowles, J. H., Gillis, D. B., Miller, W. D. 2009. Interpretation of absorption bands in airborne hyperspectral radiance data. Sensors, 9(4), 29072925, doi: 10.3390/s90402907.

Szekielda, K. H. 2012. Hyperspectral observations of internal waves. International Journal of Geology, Earth and Environmental Sciences, 2(1), 79-82, ISSN: 22772081.

Tofiño, V. 1832. Derrotero de las costas de España en el Mediterráneo y su correspondiente de África. Dirección de Hidrografía, Madrid, Spain.

Toming, K., Kutser, T., Laas, A., Sepp, M., Paavel, B., Nõges, T. 2016. First Experiences in Mapping Lake Water Quality Parameters with Sentinel-2 MSI Imagery. Remote Sens., 8, 640.

Tsimplis, M.N. 2000. Vertical structure of tidal currents over the Camarinal Sill at the Strait of Gibraltar. Journal of Geophysical Research, 105(C8), 19709-19728, doi: 10.1029/2000JC900066. 
Vázquez, A., Bruno, M., Izquierdo, A., Macías, D., Ruiz-Cañavate, A. 2008. Meteorologically forced subinertial flows and internal wave generation at the main sill of the Strait of Gibraltar. Deep Sea Research Part I: Oceanographic Research Papers, 55(10), 1277-1283, doi: 10.1016/j.dsr.2008.05.008.

Vázquez, A., Flecha, S., Bruno, M., Macías, D., Navarro, G. 2009. Internal waves and short-scale distribution patterns of chlorophyll in the Strait of Gibraltar and Alborán Sea. Geophysical Research Letters, 36(23), doi: 10.1029/2009GL040959.

Vázquez, A., Mejias, M. B., Gomez-Enri, J., Mariscal, L. 2004. Use of SAR images in the determination of internal wave parameters: an application case to the Strait of Gilbraltar. In: Proceedings SPIE 5569, Remote Sensing of the Ocean and Sea Ice, 36-43, International Society for Optics and Photonics, doi: 10.1117/12.565670.

Vázquez, A., Stashchuk, N., Vlasenko, V., Bruno, M., Izquierdo, A., Gallacher, P.C. 2006. Evidence of multimodal structure of the baroclinic tide in the Strait of Gibraltar. Geophysical Research Letters, 33, L17605, doi: 10.1029/2006GL026806.

Vicent, J., Sabater, N., Tenjo, C., Ruiz-Verdú, A., Delegido, J., Peña-Martínez, R., Moreno, J. 2015. HICO L1 and L2 data processing: Radiometric recalibration, atmospheric correction and retrieval of water quality parameters. In: 2015 IEEE International Geoscience and Remote Sensing Symposium (IGARSS), IEEE International, 26-31 July, 102-105, doi: 10.1109/IGARSS.2015.7325708.

Vlasenko, V., Stashchuck, N., Kolumban, H. 2005. Baroclinic Tides: Theoretical Modeling and Observational Evidence. Cambridge, UK: Cambridge University Press, 351. 
Wang, Y. H., Dai, C. F., Chen, Y. Y. 2007. Physical and ecological processes of internal waves on an isolated reef ecosystem in the South China Sea. Geophysical Research Letters, 34, L18609, doi: 10.1029/2007GL030658.

Watson, G., Robinson, I. S. 1990. A study of internal wave propagation in the Strait of Gibraltar using shore-based marine radar images. Journal of Physical Oceanography, 20(3), 374-395, doi: http://dx.doi.org/10.1175/15200485(1990)020<0374:ASOIWP>2.0.CO;2.

Watson, G., Robinson, I. S. 1991. A numerical model of internal wave refraction in the Strait of Gibraltar. Journal of Physical Oceanography, 21(2), 185-204, doi: http://dx.doi.org/10.1175/1520-0485(1991)021<0185:ANMOIW>2.0.CO;2.

Wesson, J. C., Gregg, M. C. 1994. Mixing at Camarinal sill in the Strait of Gibraltar. Journal of Geophysical Research: Oceans, 99(C5), 9847-9878, doi: 10.1029/94JC00256. 